\title{
An efficient of estimation stages for segmentation skin lesions based optimization algorithm
}

\author{
Nooraldeen Raaoof Hadi ${ }^{1}$, H. K. Latif ${ }^{2}$, Mohanad Aljanabi ${ }^{3}$ \\ ${ }^{1}$ Electronic Techniques Department, Institute of technology, Middle Technical University, Iraq \\ ${ }^{2,3}$ Electrical Power Techniques Engineering Department, Technical College/AL- Mausaib, \\ Al-Furat Al-Awsat Technical University, Iraq
}

\section{Article Info}

Article history:

Received Apr 2, 2020

Revised Jun 14, 2020

Accepted Jun 31, 2020

\section{Keywords:}

$\mathrm{ABC}$,

Dermatology

MASITs

M F

Segmentation

Skin lesions

\begin{abstract}
Modern dermatology distinguishes premature diagnosis for example an important part in reducing the death percentage and promising less aggressive treatment for patients. The classifications comprise various stages that must be selected suitably using the characteristics of the filter pointing to get a dependable analysis. The dermoscopic images hold challenges to be faced and overcome to enhance the automatic diagnosis of hazardous lesions. It is calculated to survey a different metaheuristic and evolutionary computing working for filter design systems. Approximately general computing techniques are observed to improve features of infect design method. Nevertheless, the median filter (MF) is normally multimodal with respect to the filter factors and so, reliable approaches that can provide optimal solutions are required. The design of MF depends on modern artificial swarm intelligence technique (MASIT) optimization algorithm which has proven to be more effective than other population-based algorithms to improve of estimation stages for segmentation skin lesions. A controlled artificial bee colony (ABC) algorithm is advanced for solving factors optimization problems and, also the physical-programming-depend on $\mathrm{ABC}$ way is applied to proposal median filter, and the outcomes are compared to another approaches.
\end{abstract}

This is an open access article under the $\underline{C C B Y-S A}$ license.

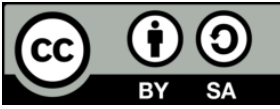

\section{Corresponding Author:}

Mohanad Aljanabi,

Electrical Power Techniques Engineering,

Technical College/AL- Mausaib, Al-Furat Al-Awsat Technical University,

Najaf, Iraq.

Email: com.mhn@atu.edu.iq

\section{INTRODUCTION}

Digital signal processing (DSP) is one of the most potent knowledges that will shape the science, engineering and technology applications [1-4]. The requirements of filter specification, order of the designed filter is commonly made-up to be very large and this leads to high power and range consumption during their applications and the researchers had carried out several extensive works on the design [5, 6]. In 2011, Karaboga $\mathrm{N}$ et al. developed a performance depend on MASITs for the design of digital filter [7]. In 2012, Erik Cuevas et al. offered depend on artificial bee colony procedure (ABC) for the automatic recognition of numerous forms and noisy images and displayed that it is better than the traditional approaches [8]. In 2012, Yimit A et al. offered a study on automatic picture improvement by ABC algorithm and this novel technique achieved better than genetic system (Gs) [9]. Yigitbasi ED et al. in their work in 2013, done out the control detection by $\mathrm{ABC}$ and the outcomes exhibited better than the approaches of Sobel and Roberts for border detection with median filter [10]. 
Khader et al. and Yang et al. in their review of works recommended that PSO and ABC algorithms have been used to several different parts for example engineering design optimizations application with Df [11, 12]. In 2017, Li et al. used ABC algorithm for multi-level thresholding of images and the experimental outcomes presented that this technique can search out the ideal thresholds efficiently and speedily, and the thresholds are very nearby to the outcomes studied by comprehensive examinations [13]. The conclusions of various investigation work points to the need of evaluating the likely of ABC, a MSITs, in applying for the problematic resolving of a subject corresponding optimization.

Digital filters (Dfs) are circuits accomplished of passing sure frequency signals to extract suitable information. The Df depending on the mechanisms used, while Df performs mathematical operations on digital signals. However, when evolutionary algorithms are applied for MF design different tests has been challenged, Figure 1 demonstrations different restrictions of evolutionary algorithm in MF design.

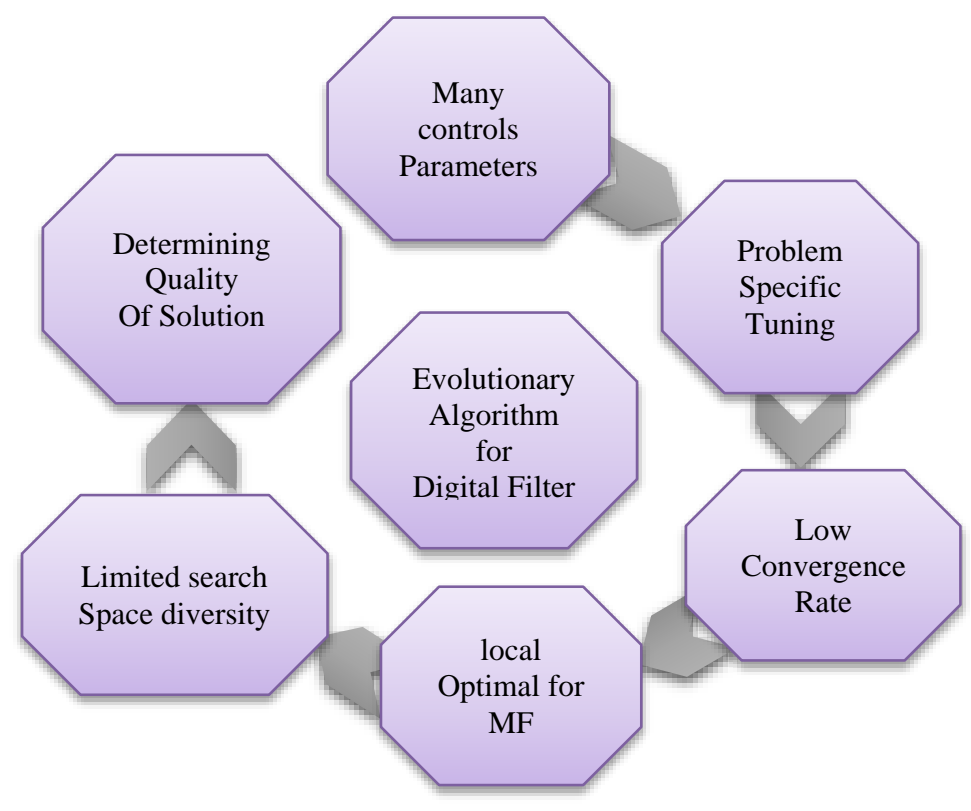

Figure 1. Restrictions of evolutionary algorithms with MF design [6]

Traditional algorithms GA, PSO, and DE comprise several control factors of these coefficients must be adjusted to their best value for finest evaluation and adjusting each of these factors for Df application. Df proposal is a calculation problematic, in which a designer attempts to novelty a group of filter factors which make available the best calculation of a wanted filter. However, it is unbearable to yield degree or stage reply of chosen to filter the standard approaches for example Butterworth system can be used for the design of optimum filters. Design of filters with random magnitude and stage response can be expressed as complex estimate problematic and can be resolved applying evolutionary procedures.

\section{METHODOLOGY}

The $\mathrm{ABC}$ algorithm is metaheuristic optimization depend on cooperative intelligent biological performance of honey colonies. There are numerous informs used to the ABC algorithm to enhance its speed, and diversity in inhabitants. Key test in enhancing the evaluation of optimization difficulties is to discovery the accurate equilibrium between exploration and exploitation. The diagram illustration of foraging performance of honey bees as shown in Figure 2.

Currently, optimal and intelligent design methods are energetic in practically very ranges of engineering. Engineers are attempting to variety outlines and representations additional skillful and intelligent. This work arrangements with a comprehensive study on design of many Dfs using optimization systems. The design of a digital filter that contents completely the essential situations perfectly is a challenging parameter. Thus, apart from the traditional mathematical approaches, optimization systems can be applied to proposal optimal digital filters. Table 1 shows the assessment of various types of filter approach. 


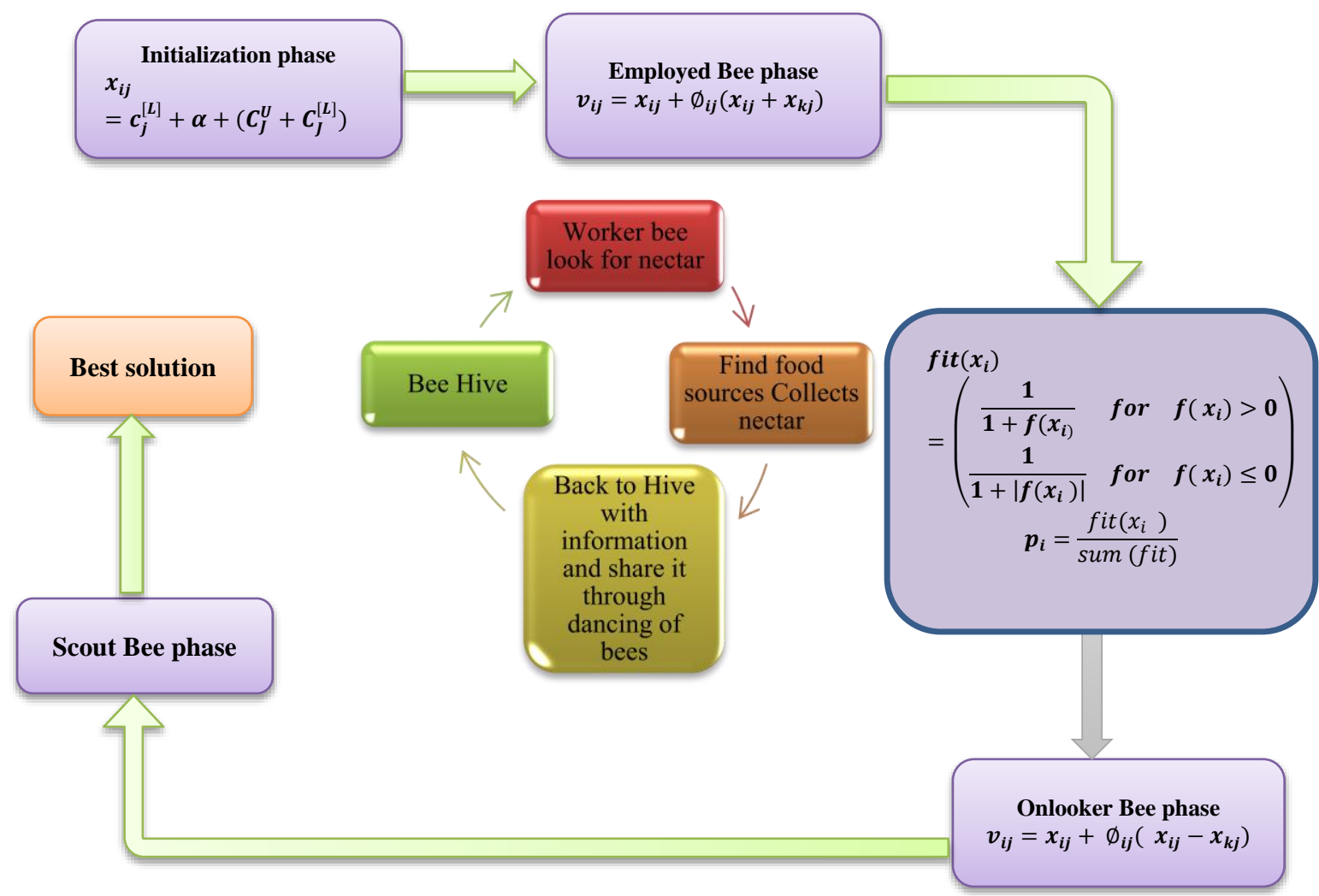

Figure 2. Representation of foraging performance of $A B C$ system

Table 1. Assessment of various types of filter approach

\begin{tabular}{|c|c|c|c|}
\hline Ref.s & Types of Filters & Optimization Method & Outcomes \\
\hline Deai et al. (2010) [14] & Digital IIR filters & $\begin{array}{l}\text { Seeker optimization } \\
\text { algorithm (SOA) }\end{array}$ & $\begin{array}{l}\text { Relaxed to recognize and easy to design of } \\
\text { examination ability. }\end{array}$ \\
\hline $\begin{array}{l}\text { Mukherjee et al. (2011) } \\
{[15]}\end{array}$ & $\begin{array}{l}\text { Linear phase low pass (LP) } \\
\text { FIR Filter Design }\end{array}$ & $\begin{array}{l}\text { Enhanced partical swarm } \\
\text { optimization (PSO) }\end{array}$ & Suitable accuracy of magnitude response \\
\hline $\begin{array}{l}\text { Meyer.Baese et al. } \\
\text { (2012) [16] }\end{array}$ & $\begin{array}{l}\text { FPGA- based full pipelined } \\
\text { FIR filter design. }\end{array}$ & Genetic Algorithm (GA) & $\begin{array}{l}\text { Design cost and internal elements are } \\
\text { decreased. }\end{array}$ \\
\hline Singh et al. (2013) [17] & IIR Filter & Predator prey optimization & It satisfies given amplitude conditions \\
\hline $\begin{array}{l}\text { Upadhyay et al. (2014) } \\
\text { [18] }\end{array}$ & $\begin{array}{l}\text { IIR Filter reduced order } \\
\text { models }\end{array}$ & craziness using PSO & Optimum resolutions for olp system \\
\hline $\begin{array}{l}\text { Dhabal and Sengupta } \\
\text { (2015) [19] }\end{array}$ & High pass FIR & $\begin{array}{l}\text { PSO with mean best } \\
\text { position }\end{array}$ & It used multi-nanoantennas \\
\hline $\begin{array}{l}\text { Aggarwal et al. (2015) } \\
{[20]}\end{array}$ & HPFIR & Real coded GA & Strategy accuracy is enhanced \\
\hline Shao et al. (2017) [21] & $\begin{array}{l}\text { (LP\&HP) FIR digital filter } \\
\text { design }\end{array}$ & $\begin{array}{l}\text { Improved PSO with } \\
\text { refraction principle }\end{array}$ & $\begin{array}{l}\text { Opposition-constructed learing refraction } \\
\text { optimal outcomes }\end{array}$ \\
\hline $\begin{array}{l}\text { Aljanabi et al. (2018) } \\
\text { [22] }\end{array}$ & Median filter (MF) & $\begin{array}{l}\text { Enhanced ABC algorithm } \\
\text { with skin lesions }\end{array}$ & $\begin{array}{l}\text { It gets high accuracy based on Artifical } \\
\text { swarm intelligence techniques with } \\
\text { healthy moles. }\end{array}$ \\
\hline $\begin{array}{l}\text { Aljanabi et al. (2019) } \\
\text { [23] }\end{array}$ & $\begin{array}{l}\text { The ABC, ASIT and } \\
\text { ASLM approaches }\end{array}$ & $\begin{array}{l}\text { Enhanced } \mathrm{ABC} \text { algorithm, } \\
\text { method and classification } \\
\text { with skin lesions }\end{array}$ & $\begin{array}{l}\text { Uses different Categories of tumors lesion } \\
\text { medical imaging } \\
\text { (STLMI) of MM and begin nevi. }\end{array}$ \\
\hline $\begin{array}{l}\text { Aljanabi et al. (2020) } \\
\text { [24] }\end{array}$ & Hybrid multi-filter & $\begin{array}{l}\text { Improved the segmentation } \\
\text { of different databases of } \\
\text { ABC }\end{array}$ & $\begin{array}{l}\text { comparisons with GA, PSO, and ASLM } \\
\text { recommend that ABC suggestions } \\
\text { improved study in evaluation to other } \\
\text { performances }\end{array}$ \\
\hline $\begin{array}{l}\text { Damilola A Okuboyejo } \\
\text { et al. (2019) [25] }\end{array}$ & Multi-filter is used. & $\begin{array}{l}\text { optimizing feature } \\
\text { assortment to decrease } \\
\text { difficulty and time- } \\
\text { consuming calculation. }\end{array}$ & $\begin{array}{l}\text { To get changing skin lesion testes with } \\
\text { classes depend on lesion categories and } \\
\text { construction. }\end{array}$ \\
\hline
\end{tabular}




\section{RESULTS AND DISCUSSIONS}

This sector offerings the simulations outcomes achieved in MATLAB R2017b of the system. $\operatorname{Order}(\mathrm{N})$ of filter is each case is taken as 20. As types of filter factors are symmetrical half of parameters has been designed in this problem. Filter should be considered with low difficulty and minimum computation time. The low power filtering methods, the range and power of the construction must be measured as a significant coefficient. Dfs with evolutionary ideas are calculated by choosing suitable factors for ilp and olp classification. In conclusion, the filter which is applied in application as apart from Figure 3.

The advance of automated systems able to support physicians in medical imaging everyday jobs has been understood to be disfigured by the existence of noise for example types of digital filtering, masking assemblies, changeability of biological figures and skins, and bubbles of imaging. These noises style an automated investigation of both microscopic and macroscopic pictures. We discussed various methods planned in the literature for determining nearly of the hesitation's outcomes from dermoscopic and clinical images. Yet, there has been a rise in the intelligences of skin tumours, in addition to clinically and dermoscopic dull nevi so, needing a careful method.

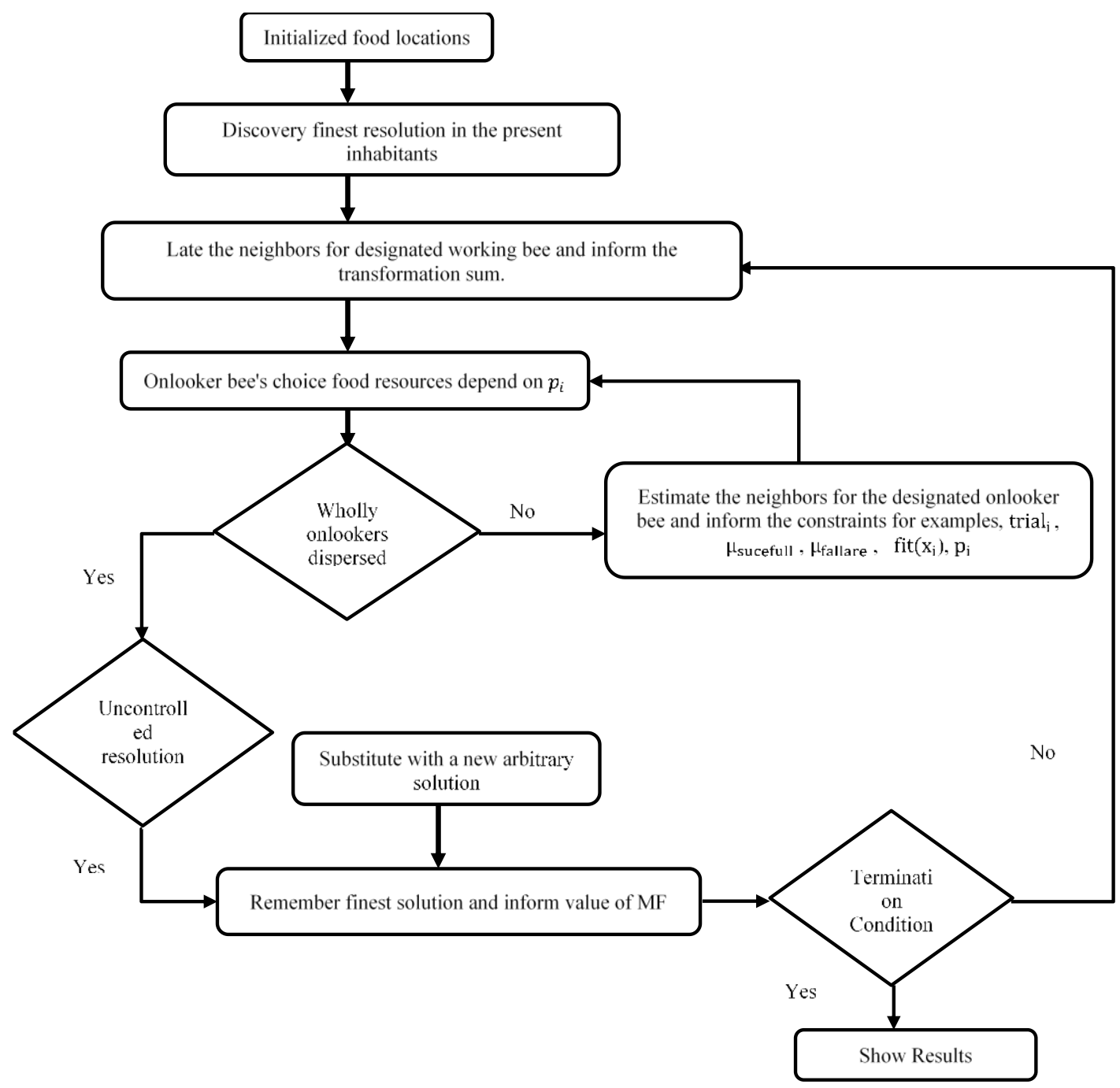

Figure 3. Diagram of optimization algorithm

The subjective views resultant from the estimation of factors used in lesion segmentation were noted as one of the problems encountered in the literature to evaluate changed automatic border detection approaches. To reach a correct measure of accuracy and dependable outcomes when performance lesion localization, we would like to commend that evaluation of segmentation methods should be completed on the identical group of lesion images [26]. 
The researchers are suggested that supplementary efforts should be geared near optimizing feature choice in order to decrease complexity and time-consuming computation [27, 28]. Numerous the classification types planned in the literature still show approximately challenges for instance unbalance between lesion image modules, the difficulty in essential selective visual structures and the effect of arrays of approximately lesion image lessons [29, 30]. We accept as true that specified a good classification prototypical, less importance could be agreed to the numeral of features essential to distinguish between lesion classes. There are many steps for improving the hybrid feature classification using segmentation of digital filter with ABC approach to make early decision of dermatology as shown in Figure 4 have been discussed. Figure 5 illustrations samples from both databases distinguished for segmentation of ranking features with filter models based on ABC approach.

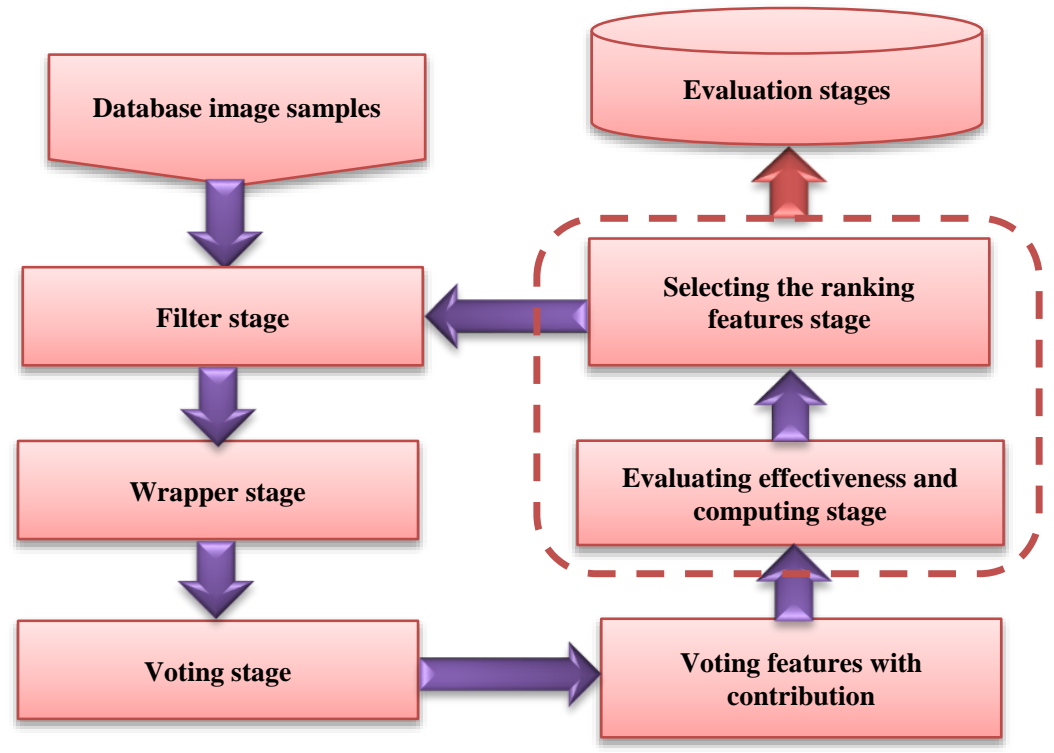

Figure 4. Steps for improving feature classification using segmentation types of filter to make early decision of dermatology and evaluation

$\boldsymbol{a}$

b

C
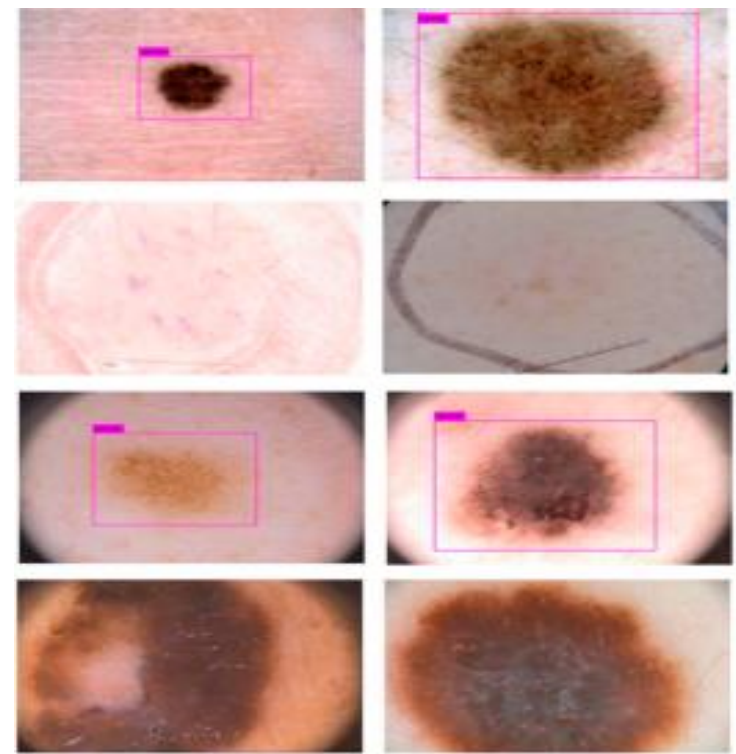

d

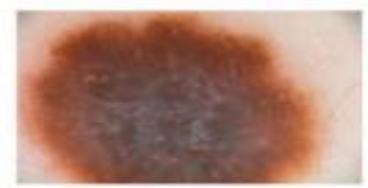

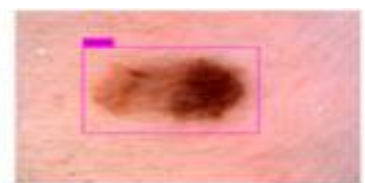
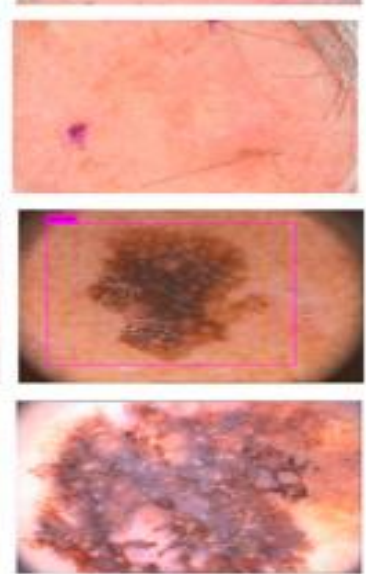

Figure 5. Outcomes of early skin lesion position detection with filter models by ABC approach, (a), (c) Are succeed acknowledgement on the ISBI 2018 and $\mathrm{PH}^{2}$, (b), (d) Show unsuccessful acknowledgements on the ISBI 2018 and $\mathrm{PH}^{2}$ 


\section{CONCLUSION AND FUTURE WORK}

There are numerous real-world problems needing instantaneous optimizations of differing purposes. MASITs are good methods for median filter proposal but another algorithm is most active than these algorithms. Then if apply the undeveloped category algorithms is substituted by hybrid or progressive algorithms than more improved outcomes are gotten.

This is as a result of improvement in optimization systems which make possible more accuracy in finding of appropriate factors. Therefore, to reach more enhancement in digital filter design apply of more progressive algorithms is valued or there is need of devolvement of improved accuracy algorithm by hybridization of exiting algorithm or presenting novel kind of ideas. However, adjustment in fitness function should correspondingly probable. These apprehensions have forced the requirement to provide automated segmentation method for medical analysis of skin tumors to decreasing the pointless biopsy, collective the speed of analysis and if reproducibility of sections outcomes.

\section{REFERENCES}

[1] S. K. Mitra, "Digital Signal Processing: A Computer-based Approach," 2nd ed, McGraw Hill, New York, 2001.

[2] J. G. Proakis and D. K. Manolakis, "Digital Signal Processing: Principles, Algorithms, and Applications," Prentice Hall of India, New Delhi, 1997.

[3] B. S. Nair, "Digital Signal Processing: Theory, Analysis and Digital-filter Design," Prentice-Hall of India, New Delhi, 2004.

[4] L. Tan and J. Jiang, "Digital Signal Processing: Fundamentals and Applications," Academic Press, New York, 2011.

[5] Y. Lim, et al., "Finite word length FIR filter design using integer programming over a discrete coefficient space," IEEE Transactions on Acoustics, Speech, and Signal Processing, vol. 30, no. 4, pp. 661-664, 1982.

[6] J. Tian, et al., "Hardware-efficient parallel structures for linear-phase FIR digital filter," in Proceedings of 56th IEEE International Midwest Symposium on Circuits and Systems (MWSCAS 2013), pp. 995-998, 2013.

[7] N. Karaboga and M. B. Cetinkaya, "A novel and efficient algorithm for adaptive filtering: artificial bee colony algorithm," Turkish Journal of Electrical Engineering \& Computer Sciences, vol. 19, no. 1, pp. 175-190, 2011.

[8] E. Cuevas, et al., "Multi-circle detection on images using artificial bee colony (ABC) optimization," Soft Computing, vol. 16, no. 2, pp. 281-96, 2012.

[9] A. Yimit, et al., "Automatic image enhancement by artificial bee colony algorithm," in International Conference on Graphic and Image Processing (ICGIP 2012), vol. 8768, 2013.

[10] E. D. Yigitbasi and N. A. Baykan, "Edge detection using artificial bee colony algorithm (ABC)," International Journal of Information and Electronics Engineering, vol. 3, no. 6, pp. 634-638, 2013.

[11] A. L. Bolaji, et al., "Artificial bee colony algorithm, its variants and applications: a survey," Journal of Theoretical and Applied Information Technology, vol. 47, no. 2, pp. 434-459, 2013.

[12] J. Yang, et al., "Artificial Bee Colony Algorithm for Image Restoration," in 2016 4th International Conference on Electrical \& Electronics Engineering and Computer Science (ICEEECS 2016), pp. 968-973, 2016.

[13] L. Li, et al., "A quick artificial bee colony algorithm for image thresholding," Information, vol. 8, no. 1, pp. 16-34, 2017.

[14] C. Dai, et al., "Seeker optimization algorithm (SOA) for digital IIR filter design," IEEE transactions on industrial electronics, vol. 57, no. 5, pp. 1710-1718, 2010.

[15] S. Mukherjee, et al., "Linear phase low pass FIR filter design using improved particle swarm optimization," in 2011 IEEE Student Conference on Research and Development (Scored), pp. 358-363, 2011.

[16] U. Meyer-Baese, et al., "Optimization of high-speed pipelining FPGA-based FIR filter design using genetic algorithm," in Independent Component Analyses, Compressive Sampling, Wavelets, Neural Net, Biosystems, and Nanoengineering $X$, vol. 8401, 2012.

[17] B. Singh, et al., "Predator prey optimization method for the design of IIR filter," WSEAS Transactions on Signal Processing, vol. 9, no. 2, pp. 51-62, 2013.

[18] P. Upeadhyay, et al., "Craziness based particle swarm optimization algorithm for IIR system identification problem," AEU-International Journal of Electronics and Communications, vol. 68, no. 5, pp. 369-378, 2014.

[19] S. Dhiabal and S. Sengupta, "Efficient design of high pass FIR filter using quantum-behaved particle swarm optimization with weighted mean best position," in 2015 Third International Conference on Computer, Communication, Control and Information Technology (C3IT), pp. 1-6, 2015.

[20] A. Aggarwal, et al., "Optimal design of FIR high pass filter based on L1 error approximation using real coded genetic algorithm," Engineering Science and Technology, an International Journal, vol. 18, no. 4, pp. 594-602, 2015.

[21] P. Shao, et al., "FIR digital filter design using improved particle swarm optimization-based refraction principle," Soft Computing, vol. 21, no. 10, pp. 2631-2642, 2017.

[22] M. Aljanabi, et al., "Skin Lesion Segmentation Method for Dermoscopy Images Using Artificial Bee Colony Algorithm," Symmetry, vol. 10, no. 8, 2018.

[23] M. H. Aljanabi, et al., "Various Types of Skin Tumors Lesion Medical Imaging (STLMI) of Healthy and Unhealthy Moles a Review and Computational of: Segmentation, Classification, Methods and Algorithms," IOP Conference Series: Materials Science and Engineering, vol. 518, no. 5, 2019. 
[24] M. Aljanabi, et al., "Discrimination between Healthy and Unhealthy Mole Lesions using Artificial Swarm Intelligence," IOP Conference Series: Material Science and Engineering, vol. 671, 2020.

[25] D. A. Okuboyejo and O. O. Olugbara, "A Review of Prevalent Methods for Automatic Skin Lesion Diagnosis," The Open Dermatology Journal, vol. 12, pp. 14-53, 2018.

[26] M. Anumothu and K. Harikishore, "High-Speed FIR Filter Design using Decision Tree Algorithm with FPGA Debugging," International Journal of Innovative Technology and Exploring Engineering (IJITEE), vol. 9, no. 3, pp. 764-770, 2020.

[27] Q. Liu, et al., "Design of Pipelined IIR Filters Using Two-Stage Frequency-Response Masking Technique," IEEE Transactions on Circuits and Systems II: Express Briefs, vol. 66, no. 5, pp. 873-877, 2019.

[28] H. Hatimi, et al., "New Approach for Detecting and Tracking a Moving Object," International Journal of Electrical and Computer Engineering (IJECE), vol. 8, no. 5, pp. 3296-3303, 2018.

[29] B. Bhatkalkar, et al., "Automated fundus image quality assessment and segmentation of optic disc using convolutional neural networks," International Journal of Electrical and Computer Engineering (IJECE), vol. 10, no. 1 , pp. 816-827, 2020 .

[30] M. Takruri, et al., "PSO-SVM hybrid system for melanoma detection from histo-pathological images," International Journal of Electrical and Computer Engineering (IJECE), vol. 9, no. 4, pp. 2941-2949, 2019. 